\title{
TOWARDS A RADIOCARBON CHRONOLOGY OF THE LATE-GLACIAL: SAMPLE SELECTION STRATEGIES
}

\author{
M J C Walker ${ }^{1}$ C Bryant ${ }^{2} \bullet$ G R Coope ${ }^{3}$ D D Harkness ${ }^{4} \cdot \mathrm{J} \mathrm{J} \mathrm{Lowe}^{3} \bullet$ E M Scott $^{5}$ \\ ABSTRACT. This paper outlines a dating program designed to test the reproducibility of radiocarbon dates on different \\ materials of Late-Glacial age (plant macrofossils, fossil beetle remains, and the "humic" and "humin" chemical fractions of \\ limnic sediments) using a combination of radiometric (beta counting) and accelerator mass spectrometry (AMS) techniques. \\ The results have implications for the design of sampling strategies and for the development of improved dating protocols, both \\ of which are important if a high-precision ${ }^{14} \mathrm{C}$ chronology for the Late-Glacial is to be achieved.
}

\section{INTRODUCTION}

The transition from the last glacial to the present interglacial (the "Last Termination" or "Late-Glacial") is one of the most intensively studied episodes in the entire Quaternary. The stratigraphic record of this period is of particular interest to Quaternary science for it constitutes the best archive of the way in which earth and atmospheric processes interact during the transition from a cold ("glacial") to a warm ("interglacial") stage (Lowe and Walker 1997). A range of dating methods has been applied to this period, but by far the most widely used has been radiocarbon, and in Europe and North America, and indeed in other areas of the world also, the time-scale for environmental change during the Late-Glacial and early Holocene rests very largely on ${ }^{14} \mathrm{C}$ dating (see e.g. Lowe 1994; Walker 1995). Until the late 1980s, the majority of Late-Glacial dates were obtained by beta counting of samples of organic lake muds, but the preferred strategy now is to date plant macrofossil material by accelerator mass spectrometry (AMS). This is partly because AMS offers the prospect of dating at a much higher level of stratigraphic resolution (since it is possible to obtain dates on very small samples of material), and partly because of the widely held view that AMS dates on plant macrofossils are inherently more reliable than those obtained from the sediment matrix, as the carbon sources of the former are known and they are not composed of heterogeneous material that could be of different ages (see Lowe and Walker 2000).

Recent work in the British Isles, however, has revealed a number of problems with ${ }^{14} \mathrm{C}$ dating the Late-Glacial, for while coherent chronologies have been obtained from some sites using either AMS (e.g. Preece 1994, Lowe et al. 1995) or a combination of radiometric and AMS ${ }^{14} \mathrm{C}$ dating (e.g. Switsur and Housley 1998), inconsistencies are evident in other dating series (e.g. Lowe et al. 1988; Walker et al. in preparation). AMS ${ }^{14} \mathrm{C}$ dates on macrofossils have frequently proved to be younger than radiometric ages from the corresponding sediment matrix, a discrepancy that has usually been attributed to the influence of older carbon residues in limnic deposits (Lowe 1991). Yet there are sequences where a coherent time-scale for the Late-Glacial has been obtained from radiometric dates on bulk sediment samples, but where AMS ${ }^{14} \mathrm{C}$ dates on plant macrofossils appear to be aberrant (e.g. Walker et al, in preparation). Equally, there are other dating series where there are variations in age not only between the AMS and radiometric dates, but also between AMS ${ }^{14} \mathrm{C}$ dates on different plant macrofossils from the same stratigraphic horizons (Turney et al. 2000). These results

\footnotetext{
${ }^{1}$ Department of Archaeology, University of Wales, Lampeter, Wales SA48 7ED, United Kingdom.

Email: walker@lamp.ac.uk.

${ }^{2}$ NERC Radiocarbon Laboratory, East Kilbride, Glasgow G75 OQF, United Kingdom

${ }^{3}$ Department of Geography, Royal Holloway, University of London, Egham, Surrey TW20 0EX, United Kingdom

${ }^{4}$ Scottish Universities Environmental Research Centre, East Kilbride, Glasgow G75 0QF, United Kingdom

${ }^{5}$ Department of Statistics, University of Glasgow, Glasgow G12 8QW, United Kingdom
}

(C) 2001 by the Arizona Board of Regents on behalf of the University of Arizona RADIOCARBON, Vol 43, Nr 2, 2001, p 1007-

Proceedings of the 17th International ${ }^{14} \mathrm{C}$ Conference, edited by I Carmi and E Boaretto 
suggest, therefore, that while AMS ${ }^{14} \mathrm{C}$ dating of macrofossil materials may offer the potential for providing a more securely-based time-scale than the radiometric dating of lake sediments, a critical re-appraisal of both approaches may now be required if a reliable ${ }^{14} \mathrm{C}$ chronology for the Late-Glacial is to be developed.

\section{AIMS AND HYPOTHESES}

One way in which an evaluation of the two techniques can be carried out is to compare radiometric and AMS ${ }^{14} \mathrm{C}$ dates from the same stratigraphic horizons within a single Late-Glacial profile. Comparative ${ }^{14} \mathrm{C}$ dating of bulk sediment samples and plant macrofossils has previously been undertaken, for example at sites in The Netherlands (Törnqvist et al. 1992) and in Norway (Birks et al. 1996; Gulliksen et al. 1998), although these have been on samples of Holocene age. For the LateGlacial, there are sites where different materials (sediments, plant macrofossils, etc.) have been dated (e.g. Böttger et al. 1998; Hoek et al. 1999) but, as far as can be established, no systematic comparative ${ }^{14} \mathrm{C}$ dating programme has yet been undertaken on materials of Late-Glacial age. The aim of the present project is therefore to compare radiometric and AMS ${ }^{14} \mathrm{C}$ dates on samples taken from two Late-Glacial profiles in northern Britain; St Bees in Cumbria, and Sluggan Bog in Northern Ireland. The specific hypotheses to be tested are:

1. Statistically similar ${ }^{14} \mathrm{C}$ ages can be obtained on organic sediments using radiometric (beta counting) and AMS methods,

2. Plant macrofossils from the same stratigraphic horizon dated by AMS produce ${ }^{14} \mathrm{C}$ ages that are statistically indistinguishable from those obtained from the associated sediment matrix,

3. AMS ${ }^{14} \mathrm{C}$ dates obtained on other organic media (e.g. Coleoptera) are statistically indistinguishable from AMS dates on plant macrofossils recovered from the same stratigraphic horizons,

4. Coleoptera from the same stratigraphic horizons, but from different ecological niches, have comparable ${ }^{14} \mathrm{C}$ ages.

In this paper we present the results from the St. Bees site only. The data from Sluggan will be discussed elsewhere.

\section{THE SITE}

The site of St. Bees is located on the Cumbrian coast of northwest England (Figure 1) where the infilling of a kettle hole formed in Late Devensian till has been exposed in section by cliff erosion. The underlying bedrock is Triassic sandstone. The sedimentary sequence at the sampling point comprises, from the base, a lower sand unit, $50 \mathrm{~cm}$ of organic limnic sediment and over $2 \mathrm{~m}$ of cryoturbated minerogenic sediments. This succession is capped by a thin Holocene peat and blown sand. Previous work at the site, involving both pollen and coleopteran analysis (Walker 1956; Pearson 1962; Coope and Joachim 1980; Coope 1994), showed the sequence to be of Late-Glacial age, with the organic limnic sediments having accumulated during the Late-Glacial Interstadial (Greenland Interstadial 1/GI-1 of Björck et al. 1998 and Walker et al. 1999), while the overlying cryoturbated sediments are attributable to the Loch Lomond/Younger Dryas Stadial (Greenland Stadial 1/GS-1).

\section{FIELD AND LABORATORY METHODS}

The field program was driven by two overriding imperatives: first, high-resolution sampling of closely constrained horizons was essential, and second, in order that ${ }^{14} \mathrm{C}$ dates could be obtained from a range of materials, large quantities of sediment were required from each sampling horizon. Accordingly, a field strategy was devised whereby the sediments overlying the Late-Glacial Intersta- 


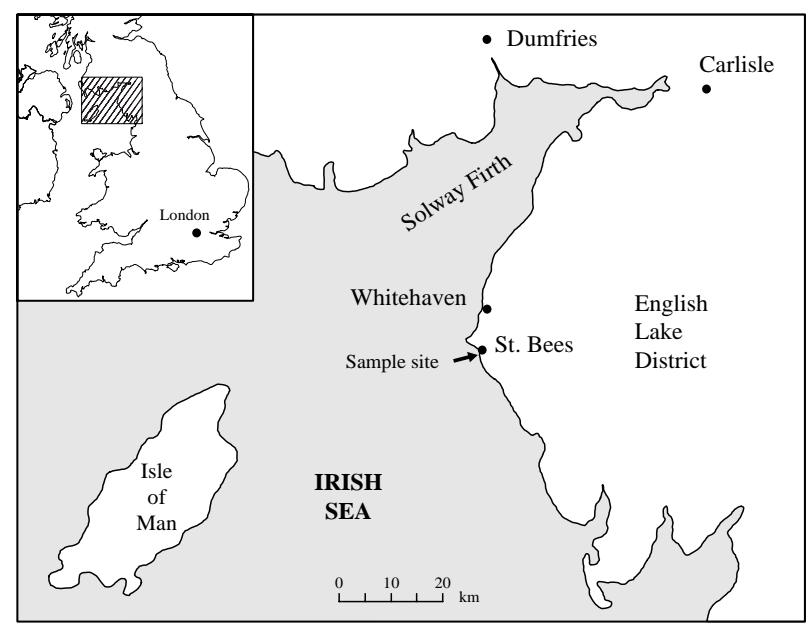

Figure 1 Location of the Late-Glacial site at St. Bees

dial organic sediments were cut back by a least $50 \mathrm{~cm}$ to expose the top of the sequence. Successive sediment increments, each measuring $2 \mathrm{~cm}$ in thickness, were then extracted sequentially down through the profile. A minimum of $1 \mathrm{~kg}$ of material was obtained from each sampling horizon. Vertical monoliths $(10 \times 10 \times 50 \mathrm{~cm})$ were also taken for pollen and LOI (loss-on-ignition) analysis.

In the laboratory, samples for LOI and for pollen analysis were removed from the monoliths at $1 \mathrm{~cm}$ intervals, and prepared using standard techniques (Bengtsson and Enell 1986; Moore et al. 1991). These data provide a litho- and biostratigraphic context for the ${ }^{14} \mathrm{C}$ dated-horizons. Samples for ${ }^{14} \mathrm{C}$ dating were taken from the $2 \mathrm{~cm}$ thick bulk sediment samples. Further sub-samples were then sieved and plant macrofossils remains, principally seeds of Cyperaceae (Carex, Eleocharis, and Scirpus) and lignified plant remains, were recovered.

Previous studies had shown that the Late-Glacial Interstadial sediments at St. Bees contained a diverse fossil coleopteran fauna (Pearson 1962; Coope and Joachim 1980). There are relatively few published reports of ${ }^{14} \mathrm{C}$ dating of fossil insect remains (e.g. Elias and Toolin 1990; Elias et al. 1991, Törnqvist et al. 1992, Cong et al. 1996), and there are none from British contexts. Fossil Coleoptera have proved to be extremely valuable proxy indicators of Late-Glacial climate (e.g. Atkinson et al. 1987; Coope et al. 1998), and hence the possibility of obtaining AMS ${ }^{14} \mathrm{C}$ ages on fossil Coleoptera constituted a potentially valuable new avenue of enquiry. Careful extraction and identification of the coleopteran remains from selected $2 \mathrm{~cm}$ samples provided species-specific samples of insect remains for dating. Although this approach inevitably produced very small samples of material and, in some instances, either a carbon yield too low for dating purposes or resultant ages with relatively large quoted errors (see below), it was felt to be worth pursuing, because of the possibility of obtaining ${ }^{14} \mathrm{C}$ dates on insects of known trophic position in the environment.

Samples for radiometric dating were prepared in the NERC Radiocarbon Laboratory at East Kilbride, under the laboratory's routine quality control procedures. The total organic content in each of the bulk sediment samples for radiometric dating was separated quantitatively into alkali soluble (humic) and alkali insoluble (humin) fractions. This enabled an assessment of the amount of any mineral (essentially ${ }^{14} \mathrm{C}$ free) carbon contained within the sediment matrix. Each sample was subjected to two digestions in $2 \mathrm{M} \mathrm{KOH}\left(80{ }^{\circ} \mathrm{C}\right.$ for $\left.24 \mathrm{hr}\right)$. The alkali-soluble fraction recovered was fil- 
tered, centrifuged to remove particulates, and acidified to precipitate the "humic" fraction. This was recovered by centrifugation, washed to neutral $\mathrm{pH}$ and dried to constant weight in a drying oven. The "humin" fraction was acidified with $2 \mathrm{M} \mathrm{HCL}\left(80^{\circ} \mathrm{C}\right.$ for $\left.24 \mathrm{hr}\right)$, washed to neutral $\mathrm{pH}$, and filtered and dried to constant weight in a drying oven. The radiometric dating programme followed routine procedures to prepare benzene for beta counting (Harkness and Wilson 1972) and employed ultralow level scintillation spectrometry. The quantitative recovery of "humic" carbon ranged between 3 and $20 \%$ by weight of the dried raw sediment. Yields of "humin" carbon were lower, in the range 2 to $11 \%$. Nevertheless, these components were recovered in sufficient quantity to allow the preparation of between 0.7 and $4.0 \mathrm{~mL}$ of benzene for radiomeric counting. In selected instances, a mgscaled separation was undertaken to allow direct, but totally independent, age comparison via ${ }^{14} \mathrm{C}$ AMS analysis.

Other sediment components for AMS dating (mainly plant macrofossils and Coleoptera) were digested in mineral acid (2M HCL) and then washed to neutral $\mathrm{pH}$. Targets for AMS measurement were prepared in East Kilbride, with quantitative recovery of the component fraction carbon by combustion in a sealed quartz tube, followed by cryogenic separation of the product $\mathrm{CO}_{2}$ (Boutton et al. 1983). Aliquots of the $\mathrm{CO}_{2}$ were converted to an iron/graphite mix (Fe:C $<3: 1$ by weight) using a Fe/Zn reduction procedure (Slota et al. 1987). Where available sample sizes were $<0.5 \mathrm{mg}$ C, additional background and known-age reference standards were prepared in the same sizes as the constrained samples, so that appropriate background corrections could be applied and tested. Batches of prepared targets (comprising samples plus their counterpart quality assurance and reference standards) were passed either to the NSF Accelerator Facility at the University of Arizona (Donahue 1990), or to the Lawrence Livermore Laboratory, California (Southon et al. 1990), for isotope mass analysis. The plant macrofossils and Coleoptera fragments yielded relatively high carbon contents, typically in the range 40 to $54 \%$ by weight. However, only the former were available in sufficient quantity to enable the preparation of optimally sized graphite targets, i.e. containing about $1.3 \mathrm{mg} \mathrm{C}$, and with sufficient excess $\mathrm{CO}_{2}$ for independent measurement of the ${ }^{13} \mathrm{C}$ enrichment. Beetle fragments were much less plentiful and the carbon recovered for graphite production was restricted to somewhere between 0.15 and $0.5 \mathrm{mg}$ per sample target. This analytical constraint is reflected in the relative magnitudes of the $1 \sigma$ confidence intervals calculated for individual age measurements.

\section{RESULTS}

\section{Pollen and LOI Data}

The principal features of the new St. Bees pollen diagram (Figure 2) are 1) the predominance of herbaceous taxa and the limited representation of woody tax below $25 \mathrm{~cm}, 2$ ) the expansion of tree birch from $25 \mathrm{~cm}$ upwards, and 3) the expansion of aquatic flora (principally Myriophyllum) in the upper part of the diagram. Comparisons with other sites in north-west Britain (e.g. Walker 1966, Pennington 1970, 1977; Johnson et al. 1972) suggest that the middle and later part of the Late-Glacial Interstadial are recorded in the sequence. The LOI record (Figure 2) is notable for two episodes of reduced organic content. The first at around $14.5 \mathrm{~cm}$ finds no clear parallels in the pollen record, whereas the second at about $28.5 \mathrm{~cm}$ is accompanied by a slight and short-lived decline in both Betula and Juniperus values. The dates from both the "humic" and plant macrofossil series (Table 1) place the latter in the time interval $11,900-12,100{ }^{14} \mathrm{C}$ BP, broadly equivalent to GI-1d (Older Dryas) of Björck et al. (1998). 


\begin{tabular}{|c|c|c|c|c|c|c|c|c|c|}
\hline \multirow{2}{*}{$\begin{array}{l}\begin{array}{c}\text { Depth } \\
(\mathrm{cm})\end{array} \\
48\end{array}$} & \multicolumn{2}{|c|}{ "Humic" age } & \multicolumn{2}{|c|}{ "Humin" age } & \multirow{2}{*}{$\begin{array}{r}\begin{array}{r}\text { Weighted } \\
\text { mean age }\end{array} \\
11,305 \pm 50\end{array}$} & \multicolumn{2}{|c|}{ Plant macrofossils } & \multicolumn{2}{|c|}{ Coleoptera } \\
\hline & $\begin{array}{l}\text { SRR-6310 } \\
\text { CAMS-57200 }\end{array}$ & $\begin{array}{l}10,790 \pm 50 \\
10,710 \pm 40\end{array}$ & SRR-6311 & $11,265 \pm 50$ & & CAMS-43634 & $10,850 \pm 60^{\mathrm{a}}$ & & \\
\hline 44 & SRR-6308 & $10,865 \pm 45$ & SRR-6309 & $11,430 \pm 65$ & $10,970 \pm 50$ & CAMS-43633 & $11,020 \pm 60^{\mathrm{a}}$ & AA-32320 & $10,195 \pm 80^{7}$ \\
\hline 38 & $\begin{array}{l}\text { SRR-6306 } \\
\text { CAMS-57199 }\end{array}$ & $\begin{array}{l}11,285 \pm 45 \\
11,210 \pm 45\end{array}$ & SRR-6307 & $11,515 \pm 60$ & $11,330 \pm 50$ & CAMS-43632 & $11,180 \pm 60^{\mathrm{a}}$ & & \\
\hline 32 & SRR-6304 & $11,860 \pm 45$ & SRR-6305 & $12,670 \pm 95$ & $12,005 \pm 55$ & CAMS-43631 & $11,700 \pm 60^{\mathrm{a}}$ & & \\
\hline 31 & & & & & & CAMS-45850 & $12,140 \pm 70^{\mathrm{e}}$ & & \\
\hline 28 & SRR-6302 & $12,155 \pm 45$ & SRR-6303 & $12,320 \pm 80$ & $12,185 \pm 55$ & CAMS-43630 & $11,940 \pm 60^{\mathrm{b}}$ & & \\
\hline 22 & SRR-6300 & $12,375 \pm 55$ & SRR-6301 & $12,625 \pm 45$ & $12,535 \pm 50$ & CAMS-43629 & $12,180 \pm 60^{\mathrm{b}}$ & $\begin{array}{l}\text { CAMS-52330 } \\
\text { AA-32318 } \\
\text { AA-32319 }\end{array}$ & $\begin{array}{l}10,640 \pm 120^{1} \\
11,190 \pm 85^{2} \\
11,535 \pm 95^{3}\end{array}$ \\
\hline 18 & $\begin{array}{l}\text { SRR-6298 } \\
\text { CAMS-57198 }\end{array}$ & $\begin{array}{l}12,530 \pm 45 \\
12,400 \pm 50\end{array}$ & SRR-6299 & $12,945 \pm 115$ & $12,610 \pm 60$ & $\begin{array}{l}\text { CAMS-43628 } \\
\text { CAMS-59480 }\end{array}$ & $\begin{array}{l}12,230 \pm 60^{\mathrm{b}} \\
12,240 \pm 40^{\mathrm{d}}\end{array}$ & $\begin{array}{l}\text { CAMS-50389 } \\
\text { CAMS-50388 } \\
\text { CAMS-50387 }\end{array}$ & $\begin{array}{l}11,850 \pm 80^{1} \\
12,160 \pm 80^{2} \\
12,160 \pm 80^{3}\end{array}$ \\
\hline 12 & SRR-6296 & $12,400 \pm 45$ & SRR-6297 & $13,110 \pm 70$ & $12,585 \pm 55$ & CAMS-43627 & $11,590 \pm 60^{c}$ & $\begin{array}{l}\text { CAMS-52329 } \\
\text { CAMS-52328 } \\
\text { AA-32316 } \\
\text { AA-32317 }\end{array}$ & $\begin{array}{c}10,940 \pm 180^{4} \\
11,370 \pm 180^{1} \\
11,780 \pm 85^{2} \\
11,860 \pm 110^{3}\end{array}$ \\
\hline 8 & $\begin{array}{l}\text { SRR-6294 } \\
\text { CAMS-57197 }\end{array}$ & $\begin{array}{l}12,375 \pm 45 \\
12,290 \pm 50\end{array}$ & SRR-6295 & $12,645 \pm 65$ & $12,440 \pm 50$ & CAMS-43626 & $12,230 \pm 60^{c}$ & $\begin{array}{l}\text { CAMS-52323 } \\
\text { CAMS-52324 } \\
\text { CAMS-52325 } \\
\text { CAMS-52326 } \\
\text { CAMS-52327 }\end{array}$ & $\begin{array}{l}10,270 \pm 210^{3} \\
11,000 \pm 170^{1} \\
11,340 \pm 140^{6} \\
11,600 \pm 140^{5} \\
11,750 \pm 120^{8}\end{array}$ \\
\hline 4 & SRR-6292 & $12,435 \pm 45$ & SRR-6293 & $12,765 \pm 75$ & $12,505 \pm 55$ & CAMS-43625 & $12,240 \pm 60^{c}$ & $\begin{array}{l}\text { CAMS-52331 } \\
\text { CAMS-52332 }\end{array}$ & $\begin{array}{r}9390 \pm 220^{6} \\
11,410 \pm 110^{2}\end{array}$ \\
\hline 1 & SRR-6290 & $12,305 \pm 45$ & SRR-6291 & $12,935 \pm 70$ & $12,460 \pm 55$ & $\begin{array}{l}\text { CAMS-43624 } \\
\text { SRR-6322 } \\
\text { SRR-6323 }\end{array}$ & $\begin{array}{l}12,020 \pm 60^{\mathrm{c}} \\
11,820 \pm 60^{\mathrm{f}} \\
12,420 \pm 105^{\mathrm{g}}\end{array}$ & & \\
\hline-0.50 & $\begin{array}{l}\text { SRR-6289 } \\
\text { CAMS-57196 }\end{array}$ & $\begin{array}{c}11,870 \pm 120 \\
12,270 \pm 50\end{array}$ & AA-30939 & $16,150 \pm 160$ & $13,060 \pm 135$ & CAMS-43623 & $12,030 \pm 60^{c}$ & & \\
\hline-7 & & & & & & CAMS-45848 & $12,230 \pm 60^{\mathrm{e}}$ & & \\
\hline
\end{tabular}




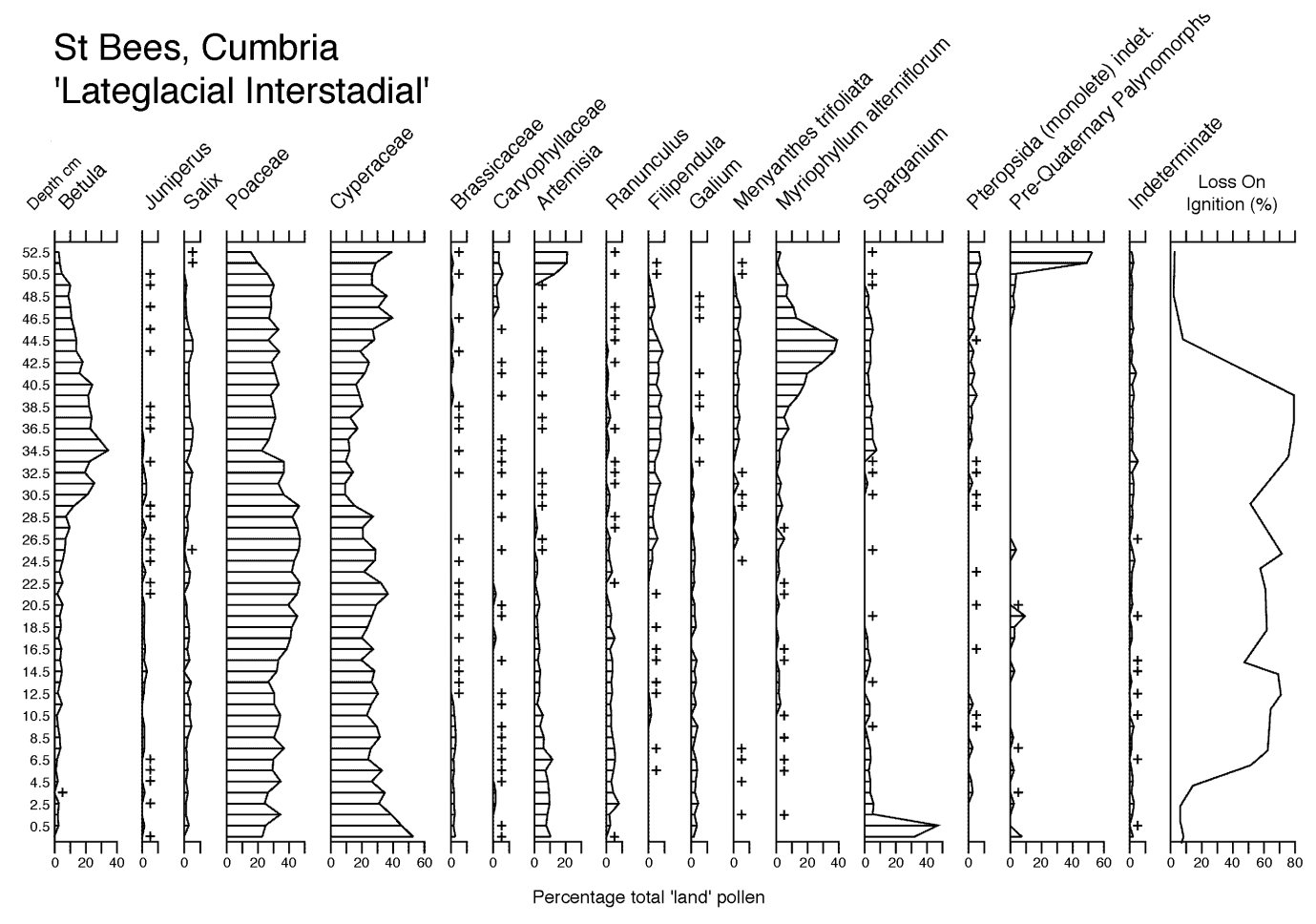

Figure 2 Late-Glacial Interstadial percentage pollen diagram from St. Bees (principal taxa only), and loss-on-ignition (LOI) values

\section{Radiocarbon Dates}

The ${ }^{14} \mathrm{C}$ data-set from St. Bees (Table 1) is the most comprehensive to be obtained from any Lateglacial sequence in Britain. It comprises 12 "humic" and 12 "humin" ages on bulk sediment samples, plus the associated weighted means; 18 AMS dates on different terrestrial plant macrofossils; and 18 AMS dates on fossil coleopteran fragments. In addition, "humic" fractions from the material of 5 samples prepared for radiometric dating have been dated by AMS.

Within most levels of the St. Bees profile, there is a significant scatter of ${ }^{14} \mathrm{C}$ age values that often exceeds the quantifiable limits of analytical confidence (quoted here at the $1 \sigma$ level). However, there does appear to be an underlying age/depth pattern (Figure 3) that is indicative of either an initial period of relatively rapid sedimentation, or a progressive temporal decline in atmospheric ${ }^{14} \mathrm{C}$ concentration $\left({ }^{14} \mathrm{C}\right.$ plateau) that coincides with changes in carbon isotope geochemistry during the middle and later part of the Late-Glacial Interstadial. Intercomparisons between the St. Bees record and that from Sluggan (unpublished) may eventually shed further light on this matter.

In all levels within the profile, the "humin" carbon yielded ages that are older than the stratigraphically contemporaneous "humic" fraction (Figures $3 \mathrm{a}$ and $3 \mathrm{~b}$ ). Although the local bedrock probably contains little, if any, older carbonaceous material, Carboniferous strata outcrop to the north and northwest of St. Bees. Hence, fragments of coal may well have been carried south-eastwards by Irish Sea ice and subsequently incorporated into the limnic deposits of the kettle hole. The influence of reworked mineral carbon in these particular Late-Glacial sediments is reflected in the older "humin" age values. Clearly, therefore, the "weighted mean" age profile (Figure $3 \mathrm{c}$ ), consisting of ${ }^{14} \mathrm{C}$ ages 
(a) Radiometrically-detemined 'humic' dates

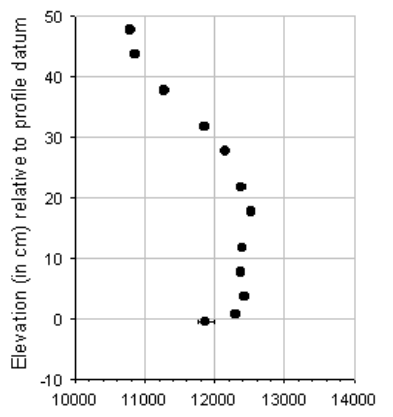

(c) Weighted mean (total carbon) dates

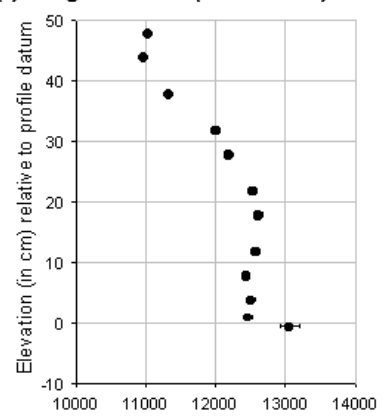

(e) AMS-determined 'humic' dates

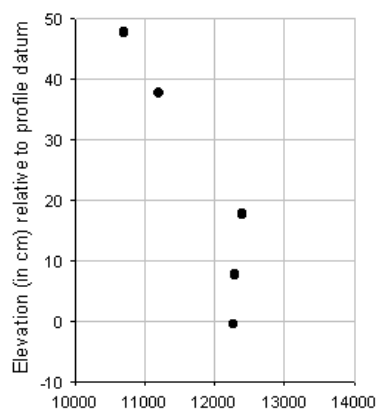

Conventional ${ }^{14} \mathrm{C}$ age (years $\mathrm{BP}$ ) (b) Radiometrically-detemined 'humin'।

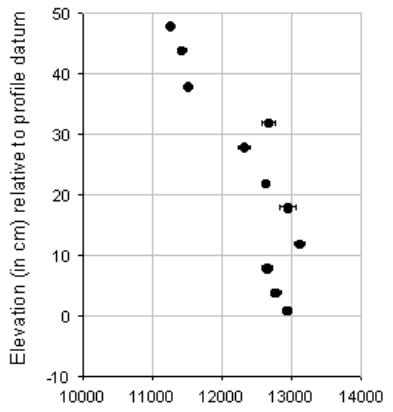

(d) AMS dates of terrestrial plant macron

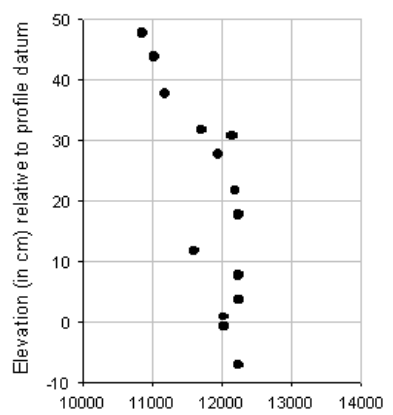

(f) AMS dates of fossil Coleoptera

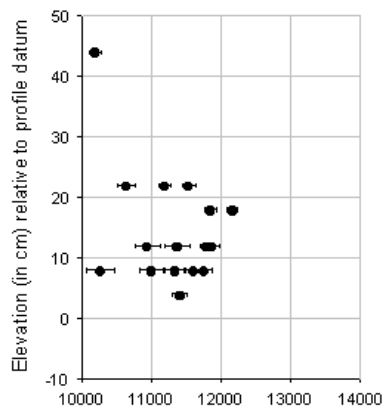

Conventional ${ }^{14} \mathrm{C}$ age (years $\left.\mathrm{BP}\right)$

Figure 3 Age depth profile for different materials from St. Bees: (a) radiometricallydetermined "humic" dates; (b) radiometrically-determined "humin" dates; (c) weighted mean (total carbon) dates; (d) AMS dates of terrestrial plant macrofossils; (e) AMSdetermined "humic" dates; (f) AMS dates of fossil Coleoptera

derived from total and/or acid washed carbon from the bulk sediment samples, does not provide a satisfactory basis for a Late-Glacial chronology for this site.

The terrestrial plant macrofossil AMS ages (Figure 3d) follow closely the radiometrically determined ages for the "humic" sediment fraction, with nine of the twelve horizons showing no statistically significant difference between "humic" and plant macrofossil age. This confirms the findings of Gullikesen et al. (1998) from the Kråkenes site in western Norway, where $\mathrm{NaOH}$ extracts from early Holocene algal gyttjas yielded ages that were consistent with those derived from terrestrial plant mac- 
rofossils. At St. Bees, a quadratic curve can be fitted to the two dating series with $\mathrm{R}^{2}$ values in excess of $90 \%$, demonstrating a consistency in pattern between the "humic" and plant macrofossil results. However, even where the two analytical strategies produced statistically concordant values, i.e. overlapping within the $95 \%(2 \sigma)$ confidence envelopes, the macrofossil ages are invariably younger by about $75{ }^{14} \mathrm{C}$ yr. Over all the horizons, the average younging effect in the plant macrofossils is in the order of about $160{ }^{14} \mathrm{C}$ yr. Working on the premise that differences associated with the isotope measurement procedures can be discounted, there are two possible explanations for this discrepancy: 1) that the "humic" ages may reflect a small, but significant, component from the older mineral carbon in these sediments, or 2) plant macrofossils can incorporate trace amounts of modern carbon, probably during the initial extraction and/or pretreatment stages of their analysis. In an attempt to resolve this problem, five sub-samples of bulk sediment were taken from those levels recording the greatest convergence and also maximum divergence in ages between the "humic" and plant macrofossil age profiles. These were pretreated on a size scale comparable with that used for the macrofossil fragments, and the recovered "humic" carbon was dated by AMS. The results (Figure 3e; Table 1, SRR/ CAMS values, column 1) show no statistically significant difference although, with the exception of the sample from $-0.5 \mathrm{~cm}$, the AMS ages display a tendency to slightly younger median values.

In the context of working hypothesis 2 above, four points emerge from these results. First, it would seem reasonable to infer that the existing "humic" and terrestrial plant macrofossil curves from St. Bees are likely to represent the respective maximum and minimum limits of the true ${ }^{14} \mathrm{C}$ chronological record; second, the close similarity between the radiometrically determined "humic" ages and the majority of the AMS plant macrofossil dates suggests that terrestrially derived macrofossils can produce an internally consistent chronology for the Late-Glacial; third, a coherent chronology can be obtained from the "humic" fraction of Late-Glacial limnic sediments, the component that, particularly in the dating of peats, has tended to be discarded in preference to the "humin" fraction; fourth, the broad measure of agreement between the radiometric and AMS dates on the "humic" sediment fractions demonstrates that closely comparable dates can be obtained on lake sediments (albeit, on the "humic" fraction only) using both radiometric and AMS methods (cf. Birks et al. 1996; Gulliksen et al. 1998).

One feature of the plant macrofossil data that perhaps merits further comment is the dating of seeds of Potamogeton from $18 \mathrm{~cm}$ in the profile. These were chosen for dating principally because an age determination was also being obtained from this horizon on a species of beetle that feeds exclusively on Potamogeton natans (see below). Previous workers have tended to avoid Potamogeton seeds as a medium for ${ }^{14} \mathrm{C}$ dating, as some species of this aquatic plant have submerged leaves, and hence subaquatic photosynthesis might introduce a hard-water error into subsequent ${ }^{14} \mathrm{C}$ dates (see e.g. Törnqvist et al. 1992). In this case, however, the date on the Potamogeton seeds $(12,240 \pm 40 \mathrm{BP})$ is virtually identical to that obtained from the terrestrial seeds of Scirpus and Carex $(12,230 \pm 60 \mathrm{BP})$ but, perhaps more significantly, is almost 300 yr younger than the "humic" age determination from the same horizon. Clearly, therefore, there can be no hard-water error in this particular case. While this might have been anticipated given the nature of the bedrock geology of the site (see above), it has been suggested that glacial till may also contain older inert carbon, and that this becomes available for synthesis in recently deglaciated aquatic environments, even where there is no obvious source of older carbon in the local bedrock (Sutherland 1980). The Potamogetonaceae are a large family, and it is not certain which species was dated here, although in view of its widespread occurrence, there must be a strong possibility that the seeds are from P. natans. Potamogeton seeds are common macrofossils in many Late-Glacial sediment sequences, and while only one age determination was made on Potamogeton from the St. Bees profile, this result does suggest that seeds of Potamogeton may 
be unaffected by a hard water factor in areas not only where limestone or ancient carbonate carbon is absent from the catchment, but also where lakes developed on a substrate of glacial till.

Eight species of Coleoptera, each with distinctive ecological affinities, were selected for ${ }^{14} \mathrm{C}$ dating (Table 2). However, the results of this part of the experimental dating programme have been variable (Figure 3f). In level $18 \mathrm{~cm}$, for example, dates have been obtained on three different fossil beetle species which are closely comparable with plant macrofossil age determinations. Indeed two of the three beetle dates are statistically indistinguishable at $1 \sigma$ from the dates on the terrestrial plant macrofossils (Table 1). Curiously, the coleopteran species that feeds exclusively on P. natans, Donacia versicolorea, produced a ${ }^{14} \mathrm{C}$ age that was younger (by almost 400 years) than the age on the seeds of Potamogeton. The date on the aquatic beetle was, in turn, almost 300 years younger than the dates on the two terrestrial taxa (Adoxus obscurus and Barynotus squamosus) although their ages do just overlap at the $2 \sigma$ level of confidence. Like the Potamogeton seeds, therefore, the beetle chitin shows no evidence of a hard-water factor.

Table $2{ }^{14} \mathrm{C}$ dated Coleoptera from St. Bees and their ecological affinities

\begin{tabular}{|c|c|}
\hline Donacia versicolorea & An aquatic species living exclusively on Potamogeton natans \\
\hline Adoxus obscurus & trial species feeding exclusively on Epilobium \\
\hline Barynotus squamosus & $\begin{array}{l}\text { A terrestrial species: larvae eat roots of herbaceous vegetation; } \\
\text { adults climb trees to eat leaves }\end{array}$ \\
\hline Byrrhus sp. & A terrestraial feeders on moss (not Sphagnum) \\
\hline Carabus problematicus & A terrestrial carnivore: feeds on worms and small insect larvae \\
\hline Plagiodora versicolorea & A species feeding exclusively on Salix (also Populus) \\
\hline Otiorhynchus nodosus & $\begin{array}{l}\text { similar in appearance to Barynotus; a leaf feeder-larvae feed under- } \\
\text { ground on roots }\end{array}$ \\
\hline Agabus bipustulatus & An aquatic carnivore: feeds exclusively on range of aquatic animals \\
\hline
\end{tabular}

Elsewhere, however, the dating results are more problematical, partly because of the very large errors on some of the dates as a consequence of small sample size and commensurately low carbon yield, partly because of significant differences in age between beetle dates from the same sample horizon, and partly because of marked differences in ages between the insect dates and those obtained from other media. In the sample from $12 \mathrm{~cm}$, three of the four insect dates are statistically indistinguishable (at $2 \sigma$ ) from the date on plant macrofossils, although it should be noted that this is one of the horizons where there is a clear discrepancy between the plant macrofossil and "humic" age determination. Indeed, in spite of the relatively large confidence ranges, all four insect dates are significantly younger (at $2 \sigma$ ) than the "'humic" age measurement. In the other four horizons from which coleopteran dates have been obtained, the insect dates (despite large errors on some) are statistically significantly younger than both the plant macrofossil and "humic" age determinations from those horizons. Interestingly, a similar age discrepancy between plant macrofossils and coleopteran remains was noted by Elias et al. (1991).

Why this should be so is not at all clear. Dating was carried out on very small samples of material and hence there are the inevitable problems of high background ${ }^{14} \mathrm{C}$ and the difficulties of quantifying this background, although targets of background material were prepared in sizes comparable with those of the samples. Nevertheless, this cannot account for the apparently consistent pattern in relative order of age of the respective insect species (Table 1). In levels 12, 18, and $22 \mathrm{~cm}$, for example, Donacia versicolorea is younger in each case than Adoxus obscurus which, in turn, in two of the levels is younger than Barynotus squamosus and of an identical age in the third. Although this pat- 
tern does not appear in a fourth sample $(8 \mathrm{~cm})$, where Barynotus is younger than Donacia, these dates were on such small samples of material $(<200 \mu \mathrm{g})$ that they may be of lesser significance. It seems equally unlikely that there is a taphonomic problem involving, for example, translocation of younger material down through the profile, for while beetle chitin is relatively durable, the fossil coleopteran remains are small, and would be unlikely to survive reworking. Moreover, such a process again cannot offer a reasonable explanation for the observed pattern of ${ }^{14} \mathrm{C}$ ages of the coleopteran fossils in each particular horizon. An alternative hypothesis, therefore, is that the age variation is in some way related to the biochemistry of the fossil chitin, possibly involving the postmortem incorporation of younger organic residues into the polysaccharide lattice. Independently derived results (Hodgins (2001) highlight the fact that a significant age difference can exist between the carbon recovered from the amino acid and polysaccharide components in a specific sample of fossil exoskeleton. The partial replacement of structural amino acids by counterpart biochemical groups derived from the surrounding sediment would seem to be a possible mechanism here. Although speculative, this proposed biochemical exchange could go some way towards explaining the apparent species-related pattern of the younging effect described above. The clear physical different in exoskeleton structure between particular insect species and/or fragments, for example surface area to weight ratios, could be a significant factor in determining their susceptibility to postmortem diagenesis. Clearly, further work is now needed on the nature of beetle chitin in order to explore further the ramifications of this hypothesis (see Hodgins 2001).

Two significant points emerge from this aspect of the dating program. First, it is evident that, in certain circumstances and providing that sufficient material can be obtained, meaningful ${ }^{14} \mathrm{C}$ dates can be obtained on species-specific samples of fossil insects, Second, the age discrepancies between Coleoptera and other materials, notably plant macrofossils and "humic" sediment fractions, suggests that a diagenetic factor (resulting in younger ages) might affect insect chitin, and that this may be more pronounced in some species than in others. The implication is that the dating of aggregate samples of insect remains (e.g. Cong et al. 1996) would almost certainly produce erroneous ${ }^{14} \mathrm{C}$ ages. Furthermore, if post-depositional diagenetic changes are registered in the the insect chitin residues, the possibility cannot be excluded that similar processes might also affect plant macrofossil remains, particularly the macromolecular outer surface of seeds. This could be one explanation for the small offset in age between the plant macrofossil and "humic" age determinations referred to above.

\section{CONCLUSIONS}

The following conclusions all have implications for the design of ${ }^{14} \mathrm{C}$ dating strategies for the LateGlacial:

1. The evidence from this tightly constrained sampling programme on Late-Glacial limnic sediments shows that AMS ${ }^{14} \mathrm{C}$ dates from the same stratigraphic horizon are comparable to the radiometric results, but the data emphasise the critical importance of careful sampling in the selection of material for both AMS and radiometric dating.

2. The data not only confirm the view that the "weighted mean" ages of bulk sediment samples from Late-Glacial limnic contexts are likely to be aberrant, but also raise serious doubts about the value of the "humin" sediment fraction (which, hitherto, has been the most widely used component) in the dating of Late-Glacial events (e.g. Walker and Harkness 1990).

3. By contrast, the evidence from St. Bees suggests that, as was shown to be the case with early Holocene gyttjas (Gulliksen et al. 1998), ${ }^{14} \mathrm{C}$ dates on the "humic" sediment fraction can pro- 
vide a coherent time-scale for Late-Glacial limnic sequences. This is important because, if replicated in other profiles, it means that a viable ${ }^{14} \mathrm{C}$ chronology can still be obtained from LateGlacial sediments, even when (as is often the case) plant macrofossils are absent.

4. There is a broad measure of agreement in the trend between radiometric dates on the "humic" fraction of Late-Glacial sediments and the AMS ${ }^{14} \mathrm{C}$ age determinations on terrestrial plant macrofossils from the same stratigraphic horizon. However, there is a small, but significant (and consistent) difference in age between the plant macrofossils (younger) and the "humic" values (older). This tendency is also evident in direct intercomparisons between paired AMS and radiometric age determinations from the "humic" carbon.

5. While some of the coleopteran dates from the St. Bees sequence are comparable with independent age measurements from the same stratigraphic horizon (on terrestrial macrofossils and on the "humic" fraction of the sediment matrix), other dates are clearly aberrant. It seems unlikely that this is a product of taphonomic processes, but post-depositional diagenetic influences on the insect chitin could be a significant factor. Further work is now required on the biochemistry of insect chitin in order to explore this hypothesis. The results of such work could have important implications for the ${ }^{14} \mathrm{C}$ dating not only of fossil insect remains, but possibly also for the dating of plant macrofossils.

\section{ACKNOWLEDGMENTS}

This work was supported by NERC grant GR3/2470, and the ${ }^{14} \mathrm{C}$ dates were provided through the NERC Radiocarbon Facilities Committee. We are grateful to Simon Brewer, Chris Turney and Stefan Wastegård for their help in the field; to Ian Clewes for preparing the pollen samples; to Nick Branch and Simon Brewer for extracting the macrofossils, and for generating the LOI data; to Shaun Buckley and Justin Jacyno for assistance with the preparation of the figures; and to Brian Miller and colleagues at the NERC Radiocarbon Laboratory, East Kilbride, for processing the samples for ${ }^{14} \mathrm{C}$ dating.

\section{REFERENCES}

Atkinson TC, Briffa KR, Coope GR. 1987. Seasonal temperatures in Britain during the last 22,000 years reconstructed using beetle remains. Nature 325:587-92.

Bengtsson L, Enell M. 1986. Chemical analysis. In: Berglund BE, editor. Handbook of Holocene palaeoecology and palaeohydrology. Chichester and New York: John Wiley, p 423-54.

Birks HH, Gulliksen S, Haflidason H, Mangerud J, Possnert G. 1996. New radiocarbon dates for the Vedde Ash and the Saksunarvatn Ash from western Norway. Quaternary Research 45:119-27.

Björck S, Walker MJC, Cwynar LC, Johnsen S, Knudsen K-L, Lowe JJ, Wohlfarth B, INTIMATE group. 1998. An event stratigraphy for the Last Termination in the North Atlantic region based on the Greenland ice-core record: a proposal by the INTIMATE group. Journal of Quaternary Science 13:282-92.

Böttger T, Hiller A, Junge FW, Litt T, Mania D, Scheele N. 1998. Late Glacial stable isotope record, radiocarbon stratigraphy, pollen, and mollusc analyses from the Geiseltal area, central Germany. Boreas 27:88100 .

Boutton TW, Wong WW, Hachey DL, Lee LS, Cabrera
MP, Klein PD. 1983. Comparison of quartz and pyrex tubes for combustion of organic samples for stable isotope analysis. Analytical Chemistry 55:1832-33.

Cong S, Ashworth AC, Schwert DP. 1996. Fossil beetle evidence for a short warm interval near 40,000 yr B.P. at Titusville, Pennsylvania. Quaternary Research 45: 216-25.

Coope GR. 1994. The Lateglacial Coleoptera from St. Bees, Cumbria. In; Boardman J, Walden J, editors. Cumbria: field guide. Oxford: Quaternary Research Association. p 86-9.

Coope GR, Joachim MJ. 1980. Late glacial environmental changes interpreted from fossil Coleoptera from St Bees, Cumbria, England. In Lowe JJ, Gray JM, Robinson E, editors. Studies in the Lateglacial of NorthWest Europe. Oxford, Pergamon Press,p.55-68.

Coope GR, Lemdahl G, Lowe JJ, Walking A. 1998. Temperature gradients in northern Europe during the last glacial-Holocene transition $\left(14-9{ }^{14} \mathrm{C}\right.$ kyr BP) interpreted from coleopteran assemblages. Journal of Quaternary Science 13:419-34.

Donahue DJ. 1990. Radiocarbon analysis by accelerator mass spectrometry. International Journal of Mass 
Spectrometry and Ion Process 143:235-45.

Elias SA, Toolin LJ. 1990. Accelerator dating of a mixed assemblage of Late Pleistocene insect fossils from the Lamb Spring site, Colorado. Quaternary Research 33: $122-26$.

Elias SA, Carrar PE, Toolin LJ, Jull AJT. 1991. Revised age of deglaciation of Lake Emma based on new radiocarbon and macrofossil analyses. Quaternary Research 36:307-21.

Gulliksen S, Birks HH, Possnert G, Mangerud J. 1998. A calendar age estimate of the Younger Dryas-Holocene boundary at Kråkenes, western Norway. The $\mathrm{Ho}$ locene 8: 249-60.

Harkness DD, Wilson HW. 1972. Some applications in radiocarbon measurement at the SURRC. Proceedings of the Eighth International Conference on Radiocarbon Dating, Royal Society of New Zealand 1B. p 102.

Hodgins GWL, Hedges REM, Butters T, Robinson MA, Coope GR. 2001. Compound specific radiocarbon measurement: the purification and dating of glucosamine from sub-fossil insect remains. Radiocarbon 43(2). This issue.

Hoek WZ, Bohncke, SJP, Ganssen GM, Meijer T. 1999. Lateglacial environmental changes recorded in calcareous gyttja deposits at Gulickshof, southern Netherlands. Boreas 28:416-32.

Johnson RJ, Tallis JH, Pearson M. 1972. A temporary section through Late-Devensian sediments at Green Lane, Dalton-in-Furness, Lancashire. New Phytologist 71:533-54.

Lowe JJ. 1991. Stratigraphic resolution and radiocarbon dating of Devensian Lateglacial sediments. In: Lowe JJ, editor. Radiocarbon dating: recent applications and future potential. Quaternary Proceedings 1. Cambridge: Quaternary Research Association.p19-26.

Lowe JJ, editor. 1994. North Atlantic Seaboard Programme IGCP-253. Journal of Qaternary Science 9: 95-198.

Lowe JJ, Walker MJC. 1997. Reconstructing Quaternary environments. 2nd edition. London: Addison-WesleyLongman.

Lowe JJ, Walker MJC. 2000. Radiocarbon dating the Last Glacial-Interglacial Transition (ca. $14-9{ }^{14} \mathrm{C}$ ka $\mathrm{BP})$ in terrestrial and marine records: the need for new quality assurance protocols. Radiocarbon 42(1):5368.

Lowe JJ, Lowe S, Fowler AJ, Hedges REM, Austin TJF. 1988. Comparison of accelerator and radiometric age measurements obtained from Late Devensian Lateglacial lake sediments from Llyn Gwernan, North Wales. Boreas 17:355-69.

Lowe JJ, Coope GR, Sheldrick C, Harkness DD, Walker MJC. 1995. Direct comparison between UK temperatures and Greenland snow accumulation rates 15,00012,000 years ago. Journal of Quaternary Science 10: $175-80$.
Moore PD, Webb JE, Collinson MB. 1991. Pollen Analysis. 2nd edition. Oxford: Blackwell.

Pearson RG. 1962. Coleoptera from a Late-glacial deposit at St. Bees, West Cumberland. Journal of Animal Ecology 31:129-50.

Pennington W. 1970. Vegetation history in the NorthWest of England: a regional synthesis. In: Walker DD, West RG, editors. Studies in the vegetational history of the British Isles. Cambridge: Cambridge University Press, p 41-80.

Pennington W. 1977. The Late Devensian flora and vegetation of Britain. Philosophical Transactions of the Royal Society, London B280:247-71.

Preece RC. 1994. Radiocarbon dates from the "Allerød soil" in Kent. Proceedings of the Geologists' Association 105:111-24.

Slota PJ, Jull AJT, Linick TW, Toolin LJ. 1987. Preparation of small samples for ${ }^{14} \mathrm{C}$ accelerator targets by catalytic reduction of CO. Radiocarbon 29(3):303-6.

Southon JR, Cafe MW, Advise JC, More TL, Proctor ID, Schemata B, Vogel JS. 1990. The new LLNL AMS spectrometer. Nuclear Instruments and Methods in Physics Research B52:301-5.

Sutherland DG. 1980. Problems of radiocarbon dating deposits from newly deglaciated terrain: some examples from the Scottish Lateglacial. In: Lowe JJ, Gray JM, Robinson JE, editors. Studies in the Lateglacial of North-West Europe. Oxford: Pergamon Press. p 12338.

Switsur VR, Housley RA. 1998. Radiocarbon dating. In Preece RC, Bridgland DR, editors. Late Quaternary environmental change in north-west Europe: excavations at Holywell Coombe, South-east England. London: Chapman \& Hall. p107-19.

Törnqvist T, de Jong AFM, Oosterbaan WA, van den Borg K. 1992. Accurate dating of organic deposits by AMS ${ }^{14} \mathrm{C}$ measurement of macrofossils. Radiocarbon 34(2):566-77.

Turney CSM, Coope GR, Harkness DD, Lowe JJ, Walker MJC. 2000. Implications for the dating of Wisconsinan (Weichselian) Late-Glacial events of systematic radiocarbon age differences between terrestrial plant macrofossils from a site in SW Ireland. Quaternary Research 53:114-21.

Walker D. 1956. A Late-Glacial deposit at St. Bees, Cumberland. Quarterly Journal of the Geological Society, London 112:93-101.

Walker DD. 1966. The Late Quaternary history of the Cumberland Lowland. Philosophical Transactions of the Royal Society, London B251:1-210.

Walker MJC. 1995. Climatic changes in Europe during the last glacial/interglacial transition. Quaternary International 28:63-76.

Walker MJC, Harkness DD. 1990. Radiocarbon dating the Devensian Lateglacial in Britain: new evidence from Llanilid, South Wales. Journal of Quaternary Science 5:135-44. 
Walker MJC, Björck S, Lowe JJ, Cwynar LC, Johnsen SJ, Knudsen K-L, Wohlfarth B, INTIMATE Group. 1999. Isotopic "events" in the GRIP ice core: a stratotype for the Late Pleistocene. Quaternary Science Reviews 18:1143-50.
Walker MJC, Coope GR, Lowe JJ, Sheldrick C, Turney CSM, Harkness DD, Blockley S. The Devensian LateGlacial deposits at Llanilid, South Wales. In preparation. 